\title{
Comparing the Effects of Self-Controlled and Examiner-Controlled Feedback on Learning in Children With Developmental Coordination Disorder
}

\author{
Mohamad Hosein Zamani, ${ }^{1}$ Rouholah Fatemi, ${ }^{2, *}$ and Keyvan Soroushmoghadam ${ }^{3}$ \\ ${ }^{1}$ Department of Sport Psychology, Faculty of Physical Education and Sport Sciences, Shahid Chamran University, Ahvaz, IR Iran \\ ${ }^{2}$ Department of Neurophysiology, Physiology Research Center (PRC), Ahvaz Jundishapur University of Medical Sciences, Ahvaz, IR Iran \\ 3 Department of Physical Education, Payame Noor University, Tehran, IR Iran \\ ${ }^{*}$ Corresponding author: Rouholah Fatemi, Department of Neurophysiology, Faculty of Medicine, Physiology Research Center (PRC), Ahvaz Jundishapur University of Medical \\ Sciences, Ahvaz, IR Iran. Tel: +98-61-33738264, Fax: +98-6133738248; +98-6133361544, E-mail: r.fatemi61@gmail.com \\ Received 2015 March 21; Revised 2015 August 18; Accepted 2015 October 10.
}

\section{Abstract}

Background: Feedback can improve task learning in children with developmental coordination disorder(DCD). However, the frequency and type of feedback may play different role in learning and needs to more investigations.

Objectives: The aim of this study was to evaluate the acquisition and retention of new feedback skills in children with DCD under different frequency of self-control and control examiner feedback.

Materials and Methods: In this quasi-experimental study with pretest-posttest design, participants based on their retention were divided into four feedback groups: self-controlled feedback groups with frequencies of 50\% and75\%, experimenter controls with frequencies of 50\% and 75\%. The study sample consisted of 24 boys with DCD aged between 9 to 11 years old in Ahvaz City, Iran. Then subjects practiced 30 throwing ( 6 blocks of 5 attempts) in eighth session. Acquisition test immediately after the last training session, and then the retention test were taken. Data were analyzed using the paired t-test, ANOVA and Tukey tests.

Results: The results showed no significant difference between groups in the acquisition phase $(\mathrm{P}>0.05)$. However,in the retention session, group of self-control showed better performance than the control tester group $(\mathrm{P}<0.05)$.

Conclusions: Based on the current findings, self-control feedback with high frequency leads to more learning in DCD children. The results of this study can be used in rehabilitation programs to improve performance and learning in children with DCD.
\end{abstract}

Keywords: Delirium, ECT, Methamphetamine Induced Withdrawal

\section{Background}

Some children with mobility problems have some characteristics including delayed motor development, balance disorder, cognitive disorder, physical inexperience, poor motor coordination, and some have mild neurological impairment (1). Developmental coordination disorder (DCD) is the second most common disorders that is prevalent among school age children and reported to be $6 \%$ (2). This disorder involves impairments in gross motor skills, fine and gross motor coordination. According to DSM-IV-TR, motor coordination disorder is a significant impairment in coordination that affects achievement of specific daily activities such as clothing, brushing, and participation in sports activities and games. The disorder is not caused by a medical disorder, or a developmental delay is incompatible with normal growth. The main features of DCD defined as low performance and poor coordination than the expected person's age and intelligence in daily activities (3).

Theories of motor control and motor learning, suggest Basal Ganglia, cerebellum and frontal lobe are involvement in DCD (4). Many children with disabilities and poor mot or coordination are referred to occupational therapists that some of these children are known as DCD. It is estimated that $2 \%-15 \%$ of children are diagnosed with the disorder (5), DCD prevalence rates in age 7 is around $5 \%$ - $6 \%$ (6), and according to reports, sons are likely diagnosed with this disorder 3 to 7 times more than girls (7).

Despite these features, a number of studies on motor learning progress of these children with developmental delays have been conducted by a number of researchers and showed promising results caused by a feedback factor. For example, Rice and Hernandez (8) in a research on children with developmental delays found that feedback improve these children's motor and learning skills and have a significant impact. Similarly, Wiliston et al. (9) also showed that the feedback information is a key factor in their learning progress. The importance of feedback for learning and performance is evident across all theoretical approaches such as Grounded - goal theory (10), control theory (11) and social cognitive theory (12). Feedback shows that how much effort is required to achieve specific goals for the task; therefore, they learned effective

Copyright (C) 2015, Mazandaran University of Medical Sciences. This is an open-access article distributed under the terms of the Creative Commons Attribution-NonCommercial 4.0 International License (http://creativecommons.org/licenses/by-nc/4.0/) which permits copy and redistribute the material just in noncommercial usages, provided the original work is properly cited. 
strategies for those tasks, the level of effort that effectively is required and revise their strategies and efforts to improve the performance $(11,13)$.

Despite these theoretical advantages of feedback, previous experimental studies have shown that feedback can have both positive and negative effects on learning and motor performance (14). Positive effects are associated with augmented feedback (KR) which used by athletes as a reference for error correction and improved subsequent performance (15). In contrast, the negative effects occur when excessive feedback is presented and caused dependency for people (16). The way of providing feedback is subject to the researchers in acquisition and learning of motor skills. According to a source of presentation, we can divide it into the teacher orientation (frequency and time of feedbacks is determined by the instructor) and subject orientation (frequency and time of receiving the feedbacks determined by the subject).

Documentary evidence indicates that the feedback with self-control methods or subject orientation improved learning of motor skills due to the effects of motivation, deeper processing of relevant information on the performance (17-19). Also, recent researches by Chiviacowsky et al. $(17,20,21)$, in self-controlled feedback express more attention in this method than other methods. Wulf and Toole (19) suggested that self- controlled feedback method will encourage participants to explore more options. Limited research has been done for self-controlled feedback in special children. For example studies of Hemayattalab et al. (22) in children with cerebral palsy showed that self-controlled group compared with examiner control group had better performance and the advantage of self-controlled was evident.

\section{Objectives}

Given that the low number of self-controlled feedback researches for abnormal persons and also the immense importance of this type of feedback and contradictory in results, the aim of this research was to determine that witch feedback method can be prioritized over the other methods (either test control or self-control), that has higher impact on education.

\section{Materials and Methods}

\subsection{Participants}

Participants were 24 individuals with DCD diagnosed with high functioning DCD (IQ: 50 - 70). The participants were selected from mental retarded children schools in Ahvaz City. Each child had to meet the criteria of DCD diagnosis on both DSM-IV (6) (Association and DSM-IV, 2000) and using basic motor ability tests, Coolidge personality and neuropsychological inventory and Riven intelligence test (23) (Lord, Rutter, and Le Couteur, 1994, Coolidge, 2002) which was examined by a child psychia- trist or psychologist. The age range of the individuals was 9 - 11 years. They were randomly selected from a group of individuals who were right-handed (because, be right handed is as important factor in throwing skills) and had no disabilities in the performing hand and also had no gross visual deficits and were all novices in the skill (throwing darts). All participants gave informed consent and their legal guardians also gave informed consent. The protocol was approved by the review board of Shahid Chamran university prior to participant recruitment, and all participants' parent provided written informed consent before participation in experimental procedures. The study was also approved by the ethics committee of Shahid Chamran university of Ahvaz.

\subsection{Apparatus and Task}

Subject's task was throwing over the shoulders with tennis balls and steer the ball toward the goal. The target was a circle with a radius of $10 \mathrm{~cm}$ that was located within 3 meters of the participants. Ten concentric circles with radii of $10,20,30 \ldots$ and 100 were drawn around the object Figure 1. These circles were used for measuring the accuracy. Participants performed the throwing task by the non-dominant hand over the shoulder with closed eyes. Scoring is 100 points for circle of $10 \mathrm{~cm}$ radius and respectively $90,80,70 \ldots 10$ for circle of $100 \mathrm{~cm}$ radius, and if the ball hits out of outer circle, subjects get score of o.Target area is divided into four quadrants, thereby it makes possible for giving the KR associated with each group based on the throwing angle and distance from the center of the goal. The four quadrants represent long, short, left or straightforward throwing, also to determine the accuracy of throwing we used the words "near" and "far", so that "near" means the circle of radius 10 to $50 \mathrm{~cm}$ and the "far" mean the circle of 60 to $90 \mathrm{~cm}$ radius. For example, if the ball hit the circle in left and 80 points, thus giving feedback will be "left-far"; If the ball hit the circle of $10 \mathrm{~cm}$ radius, subjects will be informed that the throwing has done quite well (22).

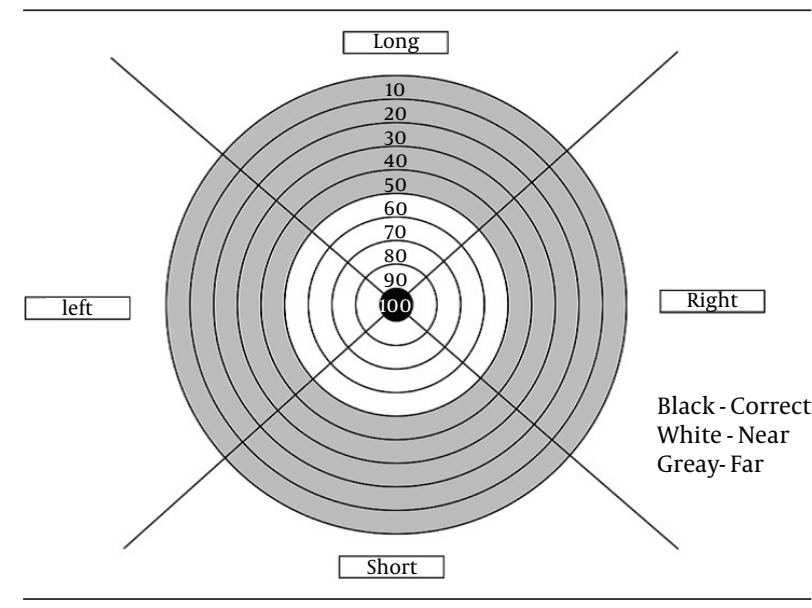

Figure 1. The Task of Study 


\subsection{Procedure}

In this quasi-experimental study with pretest-posttest design, participants based on their retention were allocated into four experimental groups: self-controlled feedback with 50\% abundance, self-controlled with $75 \%$ abundance, experimenter control feedback with abundance of 50\%, and experimenter control feedback with abundance of $75 \%$. The study population consisted of boys with DCD in Ahvaz city in 2013 that 24 subjects have been selected through objective and available method and then randomly divided into 4 groups of 6 in each. All selection and sampling processes have been performed by a clinical psychologist and an educator of children with disorder.

\subsection{Methods of Research Implementation}

Subjects practiced and then performed the task with their none-dominant hand. Distance between subjects and the center of the circle were 3 meters. One session was dedicated to train throwing skills over the shoulder. In this session, participants learned how to perform the task. After the skill has been displayed, subjects performed two blocks of five attempts at pretest and scores were recorded as pretest points. After the pretest, subjects were randomly assigned to four groups: selfcontrolled feedback with $50 \%$ of abundance, self-controlled with abundance of $75 \%$, experimenter control feedback with 50\% abundance and the experimenter control with abundance of $75 \%$.Then subjects practiced 30 throwing ( 6 blocks of 5 attempts) in eight sessions. Acquisition test and the retention test were performed immediately after the last training session. It should be noted that the acquisition and retention of feedback were removed.

\subsection{Statistical Analysis}

To analyze the obtained data, descriptive and inferential statistics were used. In the descriptive statistics mean and standard deviation of the groups in the pretest, test, acquisition and retention were calculated. Also, in the inferential statistics, paired t-test, and one-way ANOVA (analysis of variance) for acquisition and retention test and Tukey were used to determine differences between groups.

\section{Results}

Table 1 shows the descriptive results of the subjects in pretest, acquisition and retention. As the table results show, the group of self-controlled with abundant of $75 \%$ had better performance than the other groups in the retention phase. There was no significant difference between the groups in the acquisition phase.

It is noteworthy that subjects with higher scores indicating better performance. As Table 2 shows a training session with self-controlled feedback and frequency of $50 \%$ and $75 \%$ and also examiner controlled feedback with frequency of $50 \%$ and $75 \%$ have a significant effect on acquisition of over the shoulder throwing skill (examiner feedback group with frequency of 50\%, T = -12.17 and $\mathrm{P}=0.002$, self-controlled feedback group with frequency of $50 \%, \mathrm{~T}=-20.57$ and $\mathrm{P}=0.001$, examiner feedback group with frequency of $75 \%, \mathrm{~T}=-16.31$ and $\mathrm{P}=$ 0.001 , self-controlled feedback group with frequency of $75 \%, \mathrm{~T}=-21.91$ and $\mathrm{P}=000.0)$. Also, according to the average obtained in Table 1, the effect of training sessions with all four types of feedback on skill acquisition was the same and all groups showed equal improvement, and there was no difference between them in this step. As the results in Table 2 shows, the training session with self-controlled feedback and prevalence of 50\% and 75\% and also experimenter feedback control with a frequency of $50 \%$ and $75 \%$ have significant effects on retention of over the shoulder throwing skills (the examiner feedback group with frequency of $50 \%, \mathrm{~T}=-7.48$ and $\mathrm{P}=$ 0.001 , self-controlled feedback group with frequency of $50 \%, \mathrm{~T}=-16.56$ and $\mathrm{P}=0.001$, examiner feedback group with frequency of $75 \%, \mathrm{~T}=-10.88$ and $\mathrm{P}=0.000$, self-controlled feedback group with frequency of $75 \%, \mathrm{~T}=-20.08$ and $\mathrm{P}=0.000$.

Also, according to the mean obtained in Table 1, a training session with both types of self-controlled feedback (50\% and 75\%) on retention of throwing skills was more efficient than experimenter feedback control. At this point the self-controlled group showed better performance

\begin{tabular}{|c|c|c|}
\hline Groups/Stages & Number & Values $^{a}$ \\
\hline \multicolumn{3}{|c|}{ Examiner-controlled 50\% } \\
\hline Pretest & 6 & $36.83 \pm 2.43$ \\
\hline Acquisition & 6 & $60.50 \pm 3.08$ \\
\hline Retention & 6 & $47.67 \pm 1.86$ \\
\hline \multicolumn{3}{|l|}{ Self-control 50\% } \\
\hline Pretest & 6 & $39 \pm 2.36$ \\
\hline Acquisition & 6 & $61.17 \pm 1.60$ \\
\hline Retention & 6 & $55.00 \pm 1.89$ \\
\hline \multicolumn{3}{|c|}{ Examiner -controlled 75\% } \\
\hline Pretest & 6 & $39.17 \pm 3.06$ \\
\hline Acquisition & 6 & $62.50 \pm 2.34$ \\
\hline Retention & 6 & $57.17 \pm 1.94$ \\
\hline \multicolumn{3}{|l|}{ Self-control 75\% } \\
\hline Pretest & 6 & $36.17 \pm 3.18$ \\
\hline Acquisition & 6 & $64.83 \pm 2.56$ \\
\hline Retention & 6 & $69.67 \pm 3.01$ \\
\hline
\end{tabular}


than the experimenter feedback control group. Also, according to the average obtained in Table 1, the effects of training with self-controlled feedback and frequencies of $75 \%$ was much higher than the other three types in the retention phase, and more self-controlled feedback equals better learning for participants. As the results in Table 3 shows, there was no significant difference between groups in acquisition test $(\mathrm{F}=3.63, \mathrm{P}=0.030)$. However, there was asignificant difference between the groups in retention test $(\mathrm{F}=100.91, \mathrm{P}=0.000)$ that this advantage is with the experimenter and self-controlled feedback control with higher frequencies (75\%). To illustrate the status between groups, Tukey test was used. The results showed that there was no significant difference between groups in the acquisition phase. In retention, no significant difference was observed between self-controlled with $75 \%$ and self-controlled with $50 \%$ groups $(\mathrm{P}=0.001)$, self-controlled of $75 \%$ and the experimenter control of 50\% ( $\mathrm{P}=$ 0.001), and self-controlled of $75 \%$ and experimenter control of $75 \%(P=0.001)$. However, the mean of experimenter control group with $75 \%$ was higher. There was no statistically significant difference between self-controlled with $50 \%$ and experimenter control of $75 \%(P=0.358)$. The result of statistical tables showed that self-controlled group with $75 \%$ frequency was more efficient and has more advantages for learning throwing skills in children with DCD. The results of the current study showed that a higher frequency of self-controlled in feedback (75\%) has the advantage of better learning motor skills.

To better illustrate the groups at pretest, training sessions, acquisition and retention, diagram below is presented in Figure 2.

\begin{tabular}{|c|c|c|c|c|c|}
\hline Group & Tests & Values $^{a}$ & $\mathbf{T}$ & Df & Sig \\
\hline \multicolumn{6}{|l|}{ Pretest-Acquisition } \\
\hline Examiner-controlled 50\% & Pretest-Acquisition & $-23.67 \pm 4.76$ & -12.17 & 5 & .002 \\
\hline Self-controlled 50\% & Pretest-Acquisition & $-22.17 \pm 2.63$ & -20.57 & 5 & .001 \\
\hline Examiner-controlled 75\% & Pretest-Acquisition & $-23.33 \pm 3.50$ & -16.31 & 5 & .001 \\
\hline Self-controlled $75 \%$ & Pretest-Acquisition & $-28.67 \pm 3.20$ & -21.91 & 5 & .000 \\
\hline \multicolumn{6}{|l|}{ Pretest-Retention } \\
\hline Examiner-controlled 50\% & Pretest - Retention & $-10.83 \pm 3.54$ & -7.48 & 5 & .001 \\
\hline Self-controlled $50 \%$ & Pretest-Retention & $-16.00 \pm 2.36$ & -16.56 & 5 & .001 \\
\hline Examiner-controlled 75\% & Pretest-Retention & $-18.00 \pm 4.05$ & -10.88 & 5 & .000 \\
\hline Self-controlled $75 \%$ & Pretest-Retention & $-33.50 \pm 4.08$ & -20.08 & 5 & .000 \\
\hline
\end{tabular}

${ }^{\mathrm{a}}$ Data are presented as mean $\pm \mathrm{SD}$.

\begin{tabular}{|c|c|c|c|c|c|}
\hline Source & SS & df & SM & $\mathbf{F}$ & P Value \\
\hline \multicolumn{6}{|l|}{ Acquisition } \\
\hline Between group & 65.83 & 3 & 21.94 & 3.63 & .10 \\
\hline Within group & 120.66 & 20 & 6.03 & NA & NA \\
\hline Total & 186.50 & 23 & NA & NA & NA \\
\hline \multicolumn{6}{|l|}{ Retention } \\
\hline Between group & 1506.12 & 3 & 502.04 & 100.91 & .000 \\
\hline Within group & 99.50 & 20 & 4.97 & NA & NA \\
\hline Total & 1605.62 & 23 & NA & NA & NA \\
\hline
\end{tabular}

Abbreviations: df, Degree of Freedom; NA, not available; SM, Sum of Means; SS, Sum of Squares. 
Zamani MH et al.

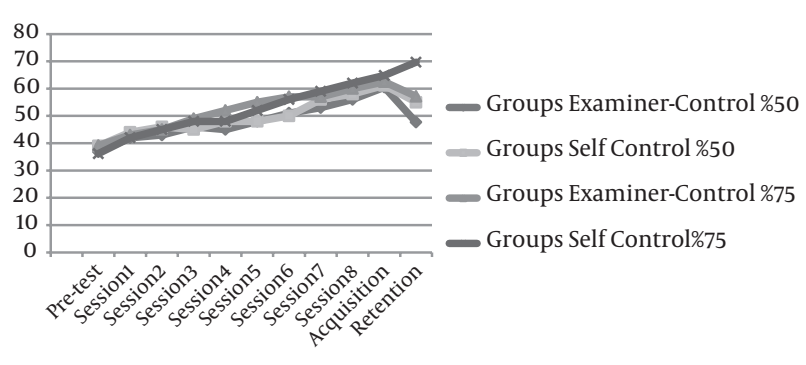

Figure 2. Results of Groups in the Pretest, Acquisition and Retention Phases

\section{Discussion}

There is no doubt that feedback concept plays an important role in the acquisition and learning motor skills (24). However, most of investigations have been for normal people. Thus, it is important that we make people understand that diverse populations in similar ways respond to feedback. Several of these studies help us in understanding of how abnormal people respond to feedback like normal people. The results of the present study will confirm the extend theory of their effect, especially the effect of self-controlled and examiner feedback frequency on learning and restraint.

The aim of this study was to compare the effects of frequencies in self-controlled and examiner feedback control on acquisition and retention of skills in children with DCD. Results of statistical analysis showed that all four training conditions on the learning of children with DCD in the test had a significant impact on acquisition and retention. As the results show a higher frequency of feedback (self-controlled (75\%) and experimenter control 75\%) effectiveness in children is higher.There are many reasons: First, learning requires the development of mechanisms to detect and correct errors automatically that in fact make learners force to compare internal feedback with external information.

Thus, a kind of meaning has given to internal feedback in which will be interpreted in the future. Since children have relatively limited experience it is expected that the regulatory facilitate with process through relatively frequent feedback that in this case it's regardless of whether or not the request is submitted. Secondly, children are different from adults in terms of information processing $(25,26)$. Developmental changes in memory (store and organize information) and the ability to use strategies (manipulating information in short-term memory) that increases from three years to adulthood has an effect on the processing speed. Thus, along with aging, the same information can be processed in less time and allows using data effectively. Limits of information processing in children can have an effect on motor learning process and particularly the use of feedback information.

Using KR to achieve better performance is improved with increasing age $(19,27)$. For example, Barclay and
Newell (28) used self-regulation intervals after providing feedback and found that 10 - 11 year old children do not effectively use these intervals, and spend more time for KR processing. Thus, exposing to more KR (higher frequency) can improve information processing and resolves this restriction and leads to more effective learning comparing to lower KR frequency (27). Finally, there is evidence indicating that in learning hard tasks, learners benefit much more from frequent feedback than reduced feedback (29). Thus, it appears that the negative effects associated with frequent feedback will reduce. Similarly, it is true to be saying that the tasks that are easy for young adults will be fairly difficult for inexperienced children. Also, you may consider the task in the present study as a difficult task for children with DCD that suffer from limitations in the balance compared to normal children.

Studies of the effect of self-controlled on a task or learning motor skills prove positive impact of self-controlled on learning. In most of these studies, the self-controlled group has been compared with non self-controlled. For example, Janelle et al. (18) were the first in the self-controlled feedback research, Wulf and Toole (19) and Wulf et al. (29) by using a skiing simulator, Chiviacowsky and Wulf (17) by using scheduling task with particular sequence, and Wulf et al. (30) in learning jump shot in basketball were used for comparison (31-34). Also, the advantages of self-controlled feedback support by Hemayattalab et al. (22) research were compared to the experimenter feedback control. Also, comparison of the two groups (self-controlled and experimenter control) in the acquisition phase showed that there was no significant difference between groups and both groups have significant progress in this step. The results is consistent with Janelle et al. (18, 35), Chiviacowsky et al. $(20,21,36)$, Wulf et al. (30), Chiviacowsky and Wulf (17) in absolute timing $(30,37,38)$, and with Chiviacowsky and Wulf (21) is relatively inconsistent in scheduling. Another did not find study that reached opposite result; therefore, series of studies show that there is no significant difference between self-controlled and experimenter feedback. The reason for this can be interpreted and explained that they analyzed self-controlled feedback in both cognitive and motivational phenomenon and stated that it is possible that these processes (cognitive and motivational) play role in superiority of self-controlled in learning process. To explain the effects of self- controlled feedback it seems that there is an inverse relationship between cognitive and motivational processes.

During training and skill acquisition, self-control subjects have more motivation. They are free for choosing target, more sense of independence and self-efficacy and for these reasons have a higher intrinsic motivation and the effort to learn. However, from the cognitive view, selfcontrolled means more pressure on subject. They have to make decisions based on knowledge of the task and their ability about learning and determine that how much feedback should be chosen? When and how to receive 
feedback? Thus, the opposite effects of cognitive and motivational processes in the acquisition on self-controlled subjects cause the same result of subjects controlled by experimenter group. However, comparing the two groups in the retention phase that both groups are in the same conditions (with no feedback) showed that self-controlled group is no more under cognitive pressure and can show the positive effects of self-control. Therefore, feedback in self-controlled can result in better performance at this step. The results of this study are consistent with the results of the most recent research in the field of motor learning effectiveness (19-21, 29, 30). Since the results of self-controlled and the experimenter control group in the acquisition phase is the same in this study, it seems that other factors may also be responsible for efficacy of self-controlled compared to the experimenter control in the retention test. Wulf and Toole (19) state that self-controlled feedback encouraged participants to seek new different motor strategies, however, for learners that feedback is controlled from the outside (i.e. in this study the time of the experimenter control group feedback was uncontrolled) these conditions is not set.

Another possibility is that self-controlled exercise is more appropriate for students with special needs that these people can ask feedback when they are hesitant about its implementation, for example, subjects in the present study after felt that their performance is not good or because of poor implementation or to ensure that they properly done or not can demand feedback. On the other hand, subjects of self-controlled feedback can receive feedback when they really need it; so, feedback can be more useful for them. Subjects under self-control conditions are appeared to have different information processes compared to those in the experimenter control group. Thus, benefits are generally not visible in the acquisition phase of testing and it is more found in retention phase that feedback is not providing (31).

In conclusion, children with DCD have poor motor coordination and performance in sports activities and the children's gross motor skills are weak. The results of the present study showed that children with DCD have the ability to learn motor skills. The ability can be approached and improved by practicing motor skills using an eight-session intervention of feedback. The results of this study showed that the benefits of self-controlled feedback, especially with a frequency greater than $75 \%$ are more than experimenter-controlled feedback. Therefore, it is recommended to coach and train teachers to use the exercise with self-controlled feedback and high-frequency. The results can be used in rehabilitation clinics and medical centers to help these children to improve their learning skills.

\section{Acknowledgments}

The authors would like to fully appreciate all parents of children with DCD, all teachers, and the school for mental retarded children in Ahvaz City, Iran, that cooperate with us in the whole process of this study.

\section{Authors' Contributions}

Mohamad Hosein Zamani conceived and designed the evaluation, collected and interpreted the clinical data, and drafted the manuscript. Rouholah Fatemi participated in designing the evaluation and drafting the manuscript and also performed the statistical analysis and revised the manuscript. Keyvan Soroushmoghadam collected and interpreted the clinical data and designed the evaluation. All three authors read and approved the final manuscript.

\section{Declaration of Interest}

Authors declare no financial support or conflict of interest.

\section{Funding/Support}

This study was supported by Jundishapur University of medical sciences and Shahid Chamran University of Ahvaz.

\section{References}

1. Geuze RH. Postural control in children with developmental coordination disorder. Neural Plast. 2005;12(2-3):183-96. doi:10.1155/ NP.2005.183. [PubMed:16097486]

2. Wuang YP, Su JH, Su CY. Reliability and responsiveness of the Movement Assessment Battery for Children-Second Edition Test in children with developmental coordination disorder. Dev Med Child Neurol. 2012;54(2):160-5. doi: 10.1111/j.1469-8749.2011.04177.x. [PubMed: 22224668]

3. Hillier S, McIntyre A, Plummer L. Aquatic physical therapy for children with developmental coordination disorder: A pilot randomized controlled trial. Phys Occup Ther Pediatr. 2010;30(2):111-24. [PubMed: 20367516]

4. Albaret JM, Chaix Y. [Neurobiological bases and neurophysiological correlates of developmental coordination disorders]. Neurophysiol Clin. 2012;42(1-2):11-7. doi: 10.1016/j.neucli.2011.07.001. [PubMed: 22200337]

5. Hong CS. Assessment for and provision of positioning equipment for children with motor impairments. Int $J$ Ther Rehabil. 2005;12(3):126-31.

6. American Psychiatric Association. Diagnostic and statistical manual of mental disorders: Text revision. Washington; American Psychiatric Association. 2000.

7. Kadesjo B, Gillberg C. Developmental coordination disorder in Swedish 7-year-old children. J Am Acad Child Adolesc Psychiatry. 1999;38(7):820-8. doi: 10.1097/00004583-199907000-00011. [PubMed:10405499]

8. Rice MS, Hernandez HG. Frequency of knowledge of results and motor learning in persons with developmental delay. Occup Ther Int. 2006;13(1):35-48. [PubMed: 16715641]

9. Wiliston $\mathrm{OH}, \mathrm{Martin} \mathrm{S}$, Holly G. The effect Knowledge of frequency feedback on motor skill learning developmental delay in a group of 16 people. OccupTher. 2006;(3):35-48.

10. Locke EA, Latham GP. A theory of goal setting $\&$ task performance. Prentice-Hall, Inc; 1990.

11. Carver CS, Scheier MF. Control theory: A useful conceptual framework for personality-social, clinical, and health psychology. Psychol Bull.1982;92(1):111-35. [PubMed: 7134324]

12. Bandura A. Social cognitive theory of self-regulation. Organiz Behav Human Decision Proc. 1991;50(2):248-87. 
13. Earley PC, Northcraft GB, Lee C, Lituchy TR. Impact of process and outcome feedback on the relation of goal setting to task performance. Acad Manag J.1990;33(1):87-105.

14. Kluger AN, DeNisi A. The effects of feedback interventions on performance: A historical review, a meta-analysis, and a preliminary feedback intervention theory. Psychol Bull. 1996;119(2):254.

15. Chen D. Trends in augmented feedback and tips for the practitioner.JPhys Educ. 2001;1:32-6.

16. Bruechert L, Lai Q, Shea $\mathrm{CH}$. Reduced knowledge of results frequency enhances error detection. Res Q Exerc Sport. 2003;74(4):467-72. doi:10.1080/02701367.2003.10609116. [PubMed:14768847]

17. Chiviacowsky S, Wulf G. Self-controlled feedback: does it enhance learning because performers get feedback when they need it? Res Q Exerc Sport. 2002;73(4):408-15. doi: 10.1080/02701367.2002.10609040. [PubMed:12495242]

18. Janelle CM, Kim J, Singer RN. Subject-controlled performance feedback and learning of a closed motor skill. Percept Mot Skills. 1995;81(2):627-34. doi: 10.2466/pms.1995.81.2.627. [PubMed: 8570369]

19. Wulf G, Toole T. Physical assistance devices in complex motor skill learning: benefits of a self-controlled practice schedule. Res Q Exerc Sport.1999;70(3):265-72. doi:10.1080/02701367.1999.10608045. [PubMed:10522284]

20. Chiviacowsky S, Godinho M, Tani G. Self-controlled knowledge of results: Effects of different schedules and task complexity. J Human Move Stud. 2005;49(4):277-96.

21. Chiviacowsky S, Wulf G, de Medeiros FL, Kaefer A, Wally R. Selfcontrolled feedback in 10-year-old children: higher feedback frequencies enhance learning. Res Q Exerc Sport. 2008;79(1):122-7. doi:10.1080/02701367.2008.10599467. [PubMed:18431958]

22. Hemayattalab R, Arabameri E, Pourazar M, Ardakani MD, Kashefi M. Effects of self-controlled feedback on learning of a throwing task in children with spastic hemiplegic cerebral palsy. Res Dev Disabil. 2013;34(9):2884-9. doi: 10.1016/j.ridd.2013.05.008. [PubMed: 23810928]

23. Coolidge FL, Thede LL, Stewart SE, Segal DL. The coolidge personality and neuropsychological inventory for children (CPNI). Preliminary psychometric characteristics. Behav Modif. 2002;26(4):55066. [PubMed: 12205827]

24. Young DE, Schmidt RA. Augmented Kinematic Feedback for Motor Learning. J Mot Behav. 1992;24(3):261-73. doi: 10.1080| 00222895.1992.9941621. [PubMed:12736131]

25. Thomas JR, Yan JH, Stelmach GE. Movement substructures change as a function of practice in children and adults. J Exp Child Psychol. 2000;75(3):228-44.doi:10.1006/jecp.1999.2535. [PubMed:10666326]

26. Wade DT, Langton-Hewer R, Wood VA, Skilbeck CE, Ismail HM. The hemiplegic arm after stroke: measurement and recovery. J Neurol Neurosurg Psychiatry. 1983;46(6):521-4. [PubMed: 6875585]

27. Wulf G, Schmidt RA. Average KR degrades parameter learning. J Mot Behav. 1996;28(4):371-81. [PubMed:14769558]

28. Barclay CR, Newell KM. Children's processing of information in motor skill acquisition. J Exp Child Psychol. 1980;30(1):98-108. [PubMed: 7391749]

29. Wulf G, Clauss A, Shea CH, Whitacre CA. Benefits of self-control in dyad practice. Res Q Exerc Sport. 2001;72(3):299-303. doi: 10.1080/02701367.2001.10608964. [PubMed:11561396]

30. Wulf G, Raupach M, Pfeiffer F. Self-controlled observational practice enhances learning. Res Q Exerc Sport. 2005;76(1):107-11. doi: 10.1080/02701367.2005.10599266. [PubMed: 15810775]

31. Butki BD, Hoffman SJ. Effects of reducing frequency of intrinsic knowledge of results on the learning of a motor skill. Percept Mot Skills. 2003;97(2):569-80. doi: 10.2466/pms.2003.97.2.569. [PubMed:14620246]

32. Ferrari M. Observing the Observer: Self-Regulation in the Observational Learning of Motor Skills. Dev Rev. 1996;16(2):203-40. doi: 10.1006/drev.1996.0008.

33. McNevin NH, Wulf G, Carlson C. Effects of attentional focus, selfcontrol, and dyad training on motor learning: implications for physical rehabilitation. Phys Ther. 2000;80(4):373-85. [PubMed: 10758522]

34. Smith RA, Lee T. Motor control and learning: a behavioural emphasis. Champaign: Human Kinetics; 1998.

35. Janelle CM, Barba DA, Frehlich SG, Tennant LK, Cauraugh JH. Maximizing performance feedback effectiveness through videotape replay and a self-controlled learning environment. Res Q Exerc Sport. 1997;68(4):269-79. doi: 10.1080/02701367.1997.10608008. [PubMed: 9421839]

36. Chiviacowsky S, Wulf G, de Medeiros FL, Kaefer A, Tani G. Learning benefits of self-controlled knowledge of results in 10-year-old children. Res Q Exerc Sport. 2008;79(3):405-10. [PubMed:18816953]

37. Wulf G, McConnel N, Gartner M, Schwarz A. Enhancing the learning of sport skills through external-focus feedback. J Mot Behav. 2002;34(2):171-82. doi: 10.1080/00222890209601939. [PubMed: 12057890]

38. Wulf $\mathrm{G}$, Shea CH.Understanding the role of augmented feedback:Skill acquisition in sport: Research, theory and practice. London: Routledge; 2004. 